\title{
Spontaneous Abortion
}

National Cancer Institute

\section{Source}

National Cancer Institute. Spontaneous Abortion. NCI Thesaurus. Code C34336.

Fetal loss at less than 20 weeks of gestation. 